\title{
EFFECTIVENESS OF DENTINAL WALL LASER TREATMENT ON RETENTION OF FIBER POST TO DIFFERENT REGIONS OF ROOT CANAL
}

\author{
Eman A. Essam*
}

\begin{abstract}
Objective: The interface between the adhesive resin and fiber posts has an important role in their performance. However, It was found that the most frequent cause of their failure is debonding at the adhesive resin-dentin interface. The aim of the present study was to evaluate the effect of dentinal wall laser treatment: Erbium, Diode or no treatment; on push out bond strength of Glassix fiber-reinforced post at different regions of root canal [cervical, middle, apical].

Materials and Methods: A total of 30 freshly extracted natural human maxillary central incisors were equally divided into three groups after root canal treatment, decoronatin and post space preparation. Teeth of group 1 were treated with Er,Cr:YSGG 2790-nm laser, group 2 were treated with 940-nm diode laser, while the teeth of group 3 [control] had no laser treatment. Glassix fiber posts were then cemented to the whole samples using Rely X Unicem 2 self adhesive resin cement. Three slices of $3 \mathrm{~mm}$ - thickness: cervical, middle and apical were prepared from each root. Then a push-out test was performed using universal testing machine at a strain rate of $0.5 \mathrm{~mm} / \mathrm{min}$. The results revealed that laser treatment generally is an important factor in attaining improvement in bond strength of fiber post to root canal dentin. The Er,Cr:YSGG -2790 nm laser afforded greater bond strength than the 940-nm diode laser. Moreover, better retention of the glass fiber-reinforced post was achievable in the coronal regions of root canals, followed by the middle, then the apical regions.
\end{abstract}

KEY WORDS: Laser; Root canal dentin; Push-out test; Post retention; Fiber reinforced post; Self-adhesive.

\section{INTRODUCTION}

Endodontically treated teeth, which have lost a large part of their structure and are subject to masticatory shearing forces need placement of a post in the root canal to provide retention for restoration. ${ }^{[1]}$ It has been demonstrated that although metal posts provide some retention for restorations, there is the possibility of severe root fractures, esthetic problems, corrosion and allergic reactions. An increase in demand for metal-free post-and-

\footnotetext{
* Assistant Professor of Fixed Prosthodontics, Faculty of Dental Medicine, Al-Azhar University, Egypt.
} 
cores has resulted in the advent of post-and-core systems without any metal, especially transparent glass or quartz fiber-reinforced composite posts. ${ }^{[2]}$ Several studies have confirmed the appropriateness of the physical properties of fiber-reinforced composite posts. The most important advantage of these posts, in addition to their esthetic results, is their modulus of elasticity which is similar to that of the tooth structure. It is believed that a modulus of elasticity similar to that of the tooth structure and the possibility of formation of an adhesive bond between various materials (root and coronal dentin, luting agents, fiber posts and composite cores) decrease the risk of root fracture..$^{[2,3]}$

Retention of fiber posts depends on several factors such as bond strength of post-resin cement and resin cement-root canal dentin. Some studies have indicated that there are no voids in the postcement interface and the bond strength of cementdentin is less than the post-cement interface. In the other words, cement-dentin interfaces is the weak point in bonded fiber posts. ${ }^{[4,5]}$ Because of various dentinal morphology in different areas of the root canal, the bonding quality is different in coronal, middle, and apical regions. On the other hand, for achieving an optimal bond in interface, adhesive and resin cement should be polymerized well. Although, it is hard to transmit light to the apical region of the root canal, dualcure adhesives may result in a more acceptable and better bond in comparison with lightcure ones. ${ }^{[6]}$

Bonding mechanism to the dentin root canal is micromechanical because of adhesive penetration to the demineralized dentinal surface and formation of hybrid layer, resin tag, and also adhesive lateral branches. ${ }^{[7]}$ The immediate bonding effectiveness of methacrylate resin cements is favourable due to the formation of a resin-dentine interdiffusion zone and resin tags that provide micromechanical interlocking between resin and demineralised root dentine. However, the technique-sensitivity ${ }^{[8]}$ and time-consuming bonding procedures associated with the use of multi- step resin cement systems compromise their popularity for clinical use. Selfadhesive resin cement systems do not require complex dentine surface pre-treatment and appear to be more well-received by clinicians for luting of glass fibre posts. However, the high cavity configuration factor (ratio between bonded and nonbonded surface areas) associated with the bonding of fibre posts to long, narrow post-spaces ${ }^{[9]}$ may result in the generation of extensive polymerisation shrinkage stresses that jeopardise the integrity of resin-dentine bonding interface. The limited ability of bond post spaces to relieve shrinkage stress by resin flow renders the retention of resin cementluted glass fibre posts unpredictable, as a substantial part of the retention is derived from friction. ${ }^{[1,8]}$

In addition to the routinely used chemical substances, other technologies have been investigated for the treatment of root canal dentine, such as laser irradiation. Lasers with a wide range of characteristics (Nd:YAG, $810 \mathrm{~nm}$ diode, Er:YAG) have been investigated in the field of endodontics to evaluate the potential of smear layer removal, antibacterial activity and sealer adhesion. [10] Recently $980 \mathrm{~nm}$ diode laser has been launched to the market. ${ }^{[11,12]}$ There are several studies that evaluate the penetration potential $[11,12,13]$ and antibacterial activity of this laser. Nevertheless, the findings of these studies are not consistent enough to elucidate their mechanism of action on root canal structures. ${ }^{[14]}$ Thus, Diode lasers emitting at 980 $\mathrm{nm}$ may have research and clinical applications because they transmit energy through thin flexible fibers that are compatible with the dimensions and curved shapes of root canals. ${ }^{[15,16]}$ Diode lasers have a good penetration potential, with high absorption peaks for melanin and hemoglobin and limited interactions with water and hydroxyapatite. The power output of these lasers ranges from 0.5 to $7 \mathrm{~W}$ and is delivered in two operating modes: continuous wave and pulsed mode. However, the endodontic applications of this technology have largely not been addressed by the literature. Coluzzi ${ }^{[17]}$ reported that 
diode lasers have a depth of penetration per pulse that is 10,000 times greater than that of the Er:YAG laser and may act more deeply within the dentinal tubules. Gutknecht et al ${ }^{[15]}$ reported that irradiation with a 980-nm diode laser can eliminate bacteria that have migrated deep into the dentine (up to $500 \mu \mathrm{m}$ ), whereas chemical solutions can only reach $100 \mu \mathrm{m}$. Ultrastructural alterations in dentine irradiated with a diode laser can be observed by scanning electron microscopy (SEM) ${ }^{[12,16,18]}$ and depend mainly on laser parameters such as output power, frequency, and application mode because these parameters are directly related to the increase in temperature in dental tissues. ${ }^{[18]}$

The Er:YAG laser (wavelength 2,940 nm) is approved by the FDA for cleaning, shaping and enlarging the root canal. ${ }^{[19]}$ Previous studies have tested the ability and the effects of this laser on root canal walls and have indicated that the Er:YAG laser is a suitable instrument for removal of the smear layer in root canals. ${ }^{[20]}$ Furthermore, George et al. in an investigation of the ability of both the Er:YAG and Er,Cr:YSGG lasers equipped with conical shaped radially firing tips and plain tips to remove the smear layer from the apical third of the root canal showed a laser activation of EDTA and a better performance of conical fibers compared to plain fibers for improving the action of EDTAC in dissolving smear layer. ${ }^{[21]}$ Hence, during the past decade, the effectiveness of lasers, including the Nd:YAG ${ }^{[22]}$, Er:YAG ${ }^{[23]}$ and Er,Cr:YSGG ${ }^{[24]}$ lasers, in the removal of tooth hard tissues and in the preparation of cavities has undergone extensive evaluation. In addition, decreases in microbial counts in the root canals have been demonstrated after laser irradiation. Therefore, laser irradiation is considered as a coadjuvant treatment for conventional root canal therapy. ${ }^{[25]}$

The aim of the present study was to evaluate the effect of dentinal wall laser treatment [whether Er,Cr: YSGG 2790-nm laser, 940-nm diode laser or no laser treatment( control)] on push out bond strength of glass fiber-reinforced post at different regions of root canal [cervical, middle, apical]. The null hypothesis tested was that there would be no difference between bond strength of laser-treated and un-treated groups. Also, there would be no difference in push out bond strength of fiber post at different root canal segments.

\section{MATERIALS AND METHODS}

A total of 30 freshly extracted sound human maxillary central incisors without any cracks or carious lesions, confirmed by evaluation with a dental explorer and under a magnifying loop were used in the present study. The teeth had been extracted due to periodontal and orthodontic reasons and were stored in saline solution of $0.9 \%$ concentration at room temperature. The teeth were collected from an oral and maxillofacial surgery department after the patients' informed consent had been obtained under a protocol approved by the Regional Medical Research Ethics Committee. Teeth with any canal obstruction or with working lengths less than $14 \mathrm{~mm}$ were excluded from the study. The teeth were decoronated $1 \mathrm{~mm}$ coronal to the cementoenamel junction after removing all the calculi and debris from the root surface using hand scalers. Micracut 150 precision cutter (Metkon instrument Ltd, Bursa, Turkey), under water coolant was used for decoronation. The canals were shaped and prepared $1 \mathrm{~mm}$ short of the apex. Firstly treated with manual K-files (Dentsply Maillefer, Ballaigues, Switzerland) from size 0.6 to 25 , in order to obtain an initial glide path, and then prepared by rotary NiTi Pro-taper mounted at c smart 3 motor (Forshan Coxo medical instrument )with instrument $\mathrm{S} 1, \mathrm{~S} 2$, F1, F2, and F3 (Dentsply-Maillefer, Ballaigues, Swiss) and $2.5 \%$ sodium hypochlorite for rinsing. The root canals were rinsed with water and dried with paper points (Meta Biomed Co. LTD, Baotou, China). They were then obturated with guttapercha (Dentsply-Maillefer, Ballaigues, Swiss) and sealer (Metabiomedco.LTD). The specimens were then embedded in a mold filled with acrylic 
resin (Acrostone, Idustrial area El-Salam city, Egypt). Each prepared root was fixed vertically in the acrylic block using a vertical holding device (Isoparallelometro motorizzato, silfradent, Itally). $10 \mathrm{~mm}$ of each canal length was prepared using no.3and no. 2 gates glidden drills with rubber stoppers (Dentsuply/Maillefer, Ballaigues, Switzerland). Size 2 Galssix post drill of $1.2 \mathrm{~mm}$ diameter was mounted at low speed hand piece (c smart 3 endomotor). The samples were then randomly divided into three groups of ten samples each. The canals in group 1 were irradiated with the Er,Cr:YSGG 2,790nm laser (Waterlase, Biolase Technology, Bayern, Germany) using an output power of $1.5 \mathrm{~W}$ and 50\% air and water level. The laser tip was changed after every four specimens. Samples of group 2 were irradiated with 940-nm Diode laser (BIOLASE, WaterLase, EPIC, ComfortPulse, EzTips) using an output power of $1.5 \mathrm{~W}$. The canals in group 3 had no laser treatment. Glassix fiber posts (Nordin- Swiss dental) were disinfected with $70 \%$ ethanol and dried with compressed air. They were then cemented to the whole samples using Rely X Unicem 2 Automix [ 3MESPE, st. Paul, MN, USA]. It is a dual curingself adhesive resin cement. It contains bi-functional (meth)acrylate. The proportion of inorganic fillers is about $43 \%$ by volume; the mixing ratio, based on volume is 1 part base paste 1 part catalyst. A specially designed load applicator device was used to employ constant pressure during post cementation. After posts' seating, light curing was performed for 40 seconds. Samples were then kept in an environment at a relative humidity of $100 \%$ for $24 \mathrm{hrs}$. All the specimens were cut perpendicular to the long axis of the root under water spray using Micracut 150 precision cutter (Metkon instrument Ltd, Bursa, Turkey), so that each root yielded three dentin/post segments (cervical, middle and apical), each with a thickness of $3 \mathrm{~mm}$. The push-out test was carried out using a custom made loading fixture (push- out jig attached to universal testing machine), ensuring that the coronal surface faced the jig and the post was centered over the hole of the jig (Fig.1). The push-out test was designed to apply a vertical load to the apical aspect of each slice via a $1 \mathrm{~mm}$ diameter cylindrical punch (plunger) mounted on a universal testing machine. A punch pin was positioned to contact only the post, without pressing the surrounding cement and/or root canal walls. The load was applied apico-coronally (towards the larger part of the root slice) on the apical surface of the slices with a crosshead speed of $0.5 \mathrm{~mm} / \mathrm{min}$ until bond failure occurred (as manifested by the extrusion of the post segment from the root).

Thus, after mounting in the custom made loading fixture, each sample was subjected to compressive loading via a computer controlled materials testing machine (Model LRX-plus; Lloyd Instruments Ltd., Fareham, UK) with a load cell of $5 \mathrm{kN}$. Data were recorded using computer software (NexygenMT; Lloyd Instruments). The load was applied by 3 plungers of different sizes $(1 \mathrm{~mm}, 0.75 \mathrm{~mm} \& 0.5$ $\mathrm{mm})$ in an apical-coronal direction because of the convergence of the root canal sections (Cervical, middle and apical). The selected diameter of the plunger was positioned so that it only contacts the post to displace it downward. This way, it was assured that the overlaying root dentine was sufficiently supported during the loading process (Fig.2). The maximum failure load was recorded in $\mathrm{N}$ and converted into $\mathrm{MPa}$. The bond strength was calculated from the recorded peak load divided by the computed surface area [as calculated by the following formula (Lopes et $\mathrm{al}^{26}$ ): Bond $=\mathrm{F} / \mathrm{A}, \quad[\mathrm{A}$ $=(\pi \mathrm{h}(\mathrm{r} 1+\mathrm{r} 2)]$, where, $\pi$ is the constant 3.14, $\mathrm{r} 1$ apical radius, $\mathrm{r} 2$ coronal one, and $\mathrm{h}$ is the thickness of the sample in millimeters. Failure was manifested by extrusion of filling material and confirmed by sudden drop along load-deflection curve recorded by the computer software. Subsequent to the push-out test, the noticed failure modes were evaluated under a magnifying loop and classified into one of the following categories: (1) adhesive failure between resin cement and root canal dentin. (2) Cohesive failure within the resin cement, or (3) mixed failure. 


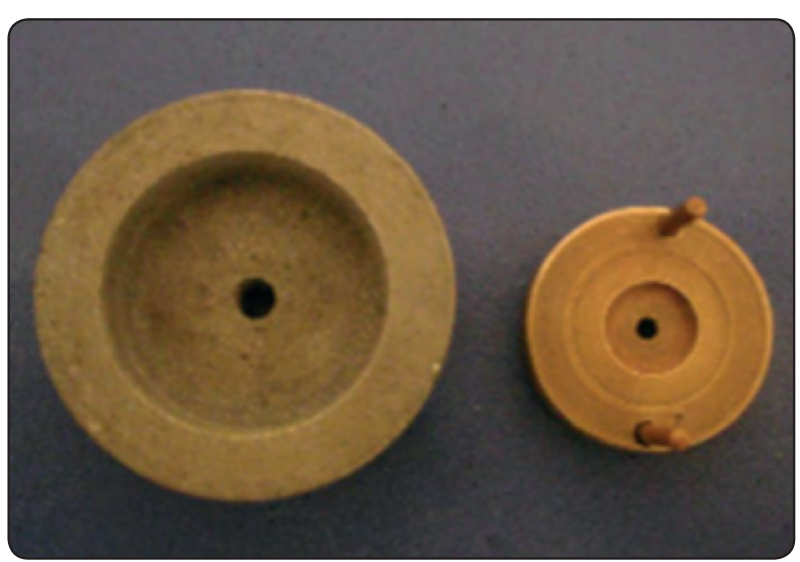

Fig. (1): Components of push-out jig.

One sample, representing each mode of failure was randomly selected and scanned under Electron Microscope (SEM: XL 30,Philips, Netherlands).

\section{RESULTS}

\section{Statistical analysis}

Recorded values were presented as mean and standard deviation (SD) values. Data were explored for normality using Kolmogorov-Smirnov test of normality. The results of Kolmogorov-Smirnov test indicated that most of data were normally distributed (parametric data). Therefore, ANOVA test was used for comparison between each 3 groups. Tukey's post hoc test was used when ANOVA yielded positive results.

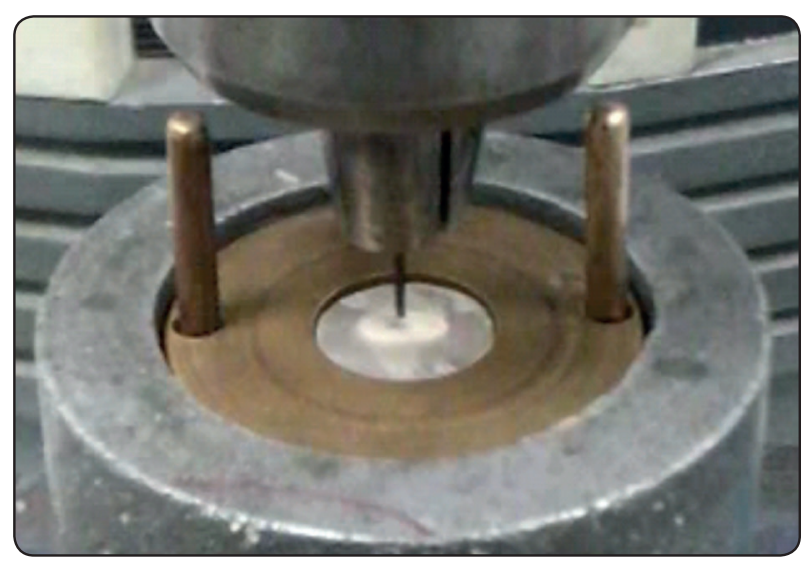

Fig. (2): Sample during load application.

The significance level was set at $p \leq 0.05$. Statistical analysis was performed with SPSS 16.0 (Statistical Package for Scientific Studies, SPSS, Inc., Chicago, IL, USA) for Windows.

\section{Comparison between different regions}

In all treatment groups, the mean greater pushout strength (MPa) was recorded in the coronal region, followed by the middle region, with the least value in the apical region. ANOVA test revealed a significant difference between different regions within the same treatment $(\mathrm{p}<0.0001)$. Tukey's post hoc test revealed a significant difference between each two regions within the same treatment (Table1, Fig.3)

TABLE (1) Values of push-out strength (MPa) in different regions within the same treatment and significance of the difference using ANOVA test:

\begin{tabular}{|c|c|c|c|c|c|c|c|c|c|}
\hline & \multicolumn{3}{|c|}{ Erbium } & \multicolumn{3}{|c|}{ Diode } & \multicolumn{3}{|c|}{ No treatment } \\
\hline & Coronal & Middle & Apical & Coronal & Middle & Apical & Coronal & Middle & Apical \\
\hline Mean & $18.29^{\mathrm{a}}$ & $17.65^{\mathrm{b}}$ & $16.94^{\mathrm{c}}$ & $13.19^{\mathrm{a}}$ & $12.81^{\mathrm{b}}$ & $11.73^{\mathrm{c}}$ & $5.04^{\mathrm{a}}$ & $4.32^{\mathrm{b}}$ & $3.60^{\mathrm{c}}$ \\
\hline SD & 0.75 & 0.49 & 0.35 & 0.38 & 0.36 & 0.65 & 0.32 & 0.39 & 0.40 \\
\hline Min & 17.00 & 16.90 & 16.40 & 12.70 & 12.30 & 10.60 & 4.50 & 3.80 & 3.00 \\
\hline Max & 19.30 & 18.20 & 17.50 & 13.90 & 13.50 & 12.60 & 5.50 & 4.90 & 4.20 \\
\hline F value & \multicolumn{3}{|c|}{14.78} & \multicolumn{3}{|c|}{24.71} & \multicolumn{3}{|c|}{37.52} \\
\hline$P$ value & \multicolumn{3}{|c|}{$<0.0001^{*}$} & \multicolumn{3}{|c|}{$<0.0001 *$} & \multicolumn{3}{|c|}{$<0.0001 *$} \\
\hline
\end{tabular}

*significant at $p<0.05$ 
TABLE (2) Values of push-out strength (MPa) in different regions within the same treatment and significance of the difference using ANOVA test:

\begin{tabular}{|c|c|c|c|c|c|c|c|c|c|}
\hline & \multicolumn{3}{|c|}{ Coronal } & \multicolumn{3}{c|}{ Middle } & \multicolumn{3}{c|}{ Apical } \\
\hline & Erbium & Diode & no treat. & Erbium & Diode & no treat. & Erbium & Diode & no treat. \\
\hline Mean & 18.29 & 13.19 & 5.04 & 17.65 & 12.81 & 4.32 & 16.94 & 11.73 & 3.60 \\
\hline SD & 0.75 & 0.38 & 0.32 & 0.49 & 0.36 & 0.39 & 0.35 & 0.65 & 0.40 \\
\hline Min & 17.00 & 12.70 & 4.50 & 16.90 & 12.30 & 3.80 & 16.40 & 10.60 & 3.00 \\
\hline Max & 19.30 & 13.90 & 5.50 & 18.20 & 13.50 & 4.90 & 17.50 & 12.60 & 4.20 \\
\hline F value & \multicolumn{3}{|c|}{1655.72} & & & 2617.81 & & 1923.38 \\
\hline P value & $<0.0001 *$ & \multicolumn{3}{c|}{$<0.0001 *$} & & $<0.0001 *$ \\
\hline
\end{tabular}

* Significant at $p<0.05$

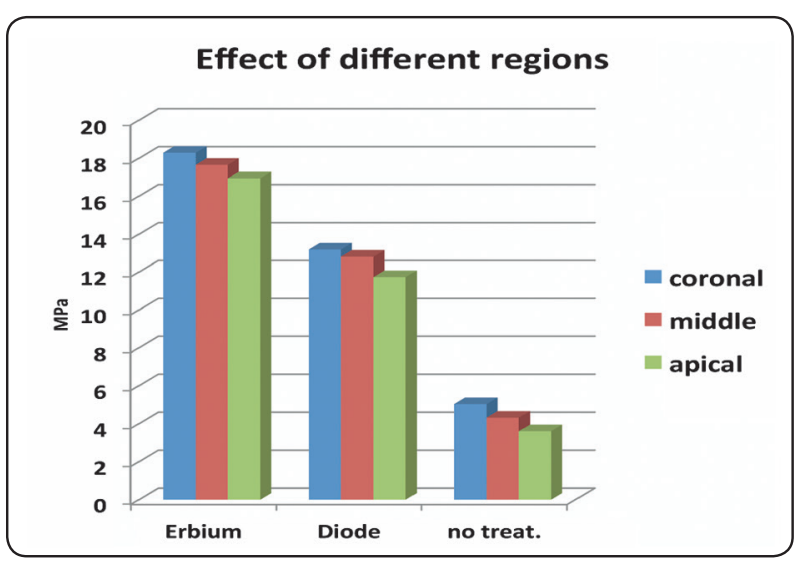

Fig. (3) Column chart showing push-out bond strength (MPa) in different regions within the same treatment

Tukey's post hoc test: Within the same treatment, means sharing the same superscript letter are not significantly different

\section{II- Comparison between different treatments}

In all regions, the mean greater push-out strength (MPa) was recorded in the erbium group, followed by the diode group, with the least value in the no treatment group. ANOVA test revealed a significant difference between different treatments within the same region $(p<0.0001)$. Tukey's post hoc test revealed a significant difference between each two treatments within the same region (Table 2, Fig.4).

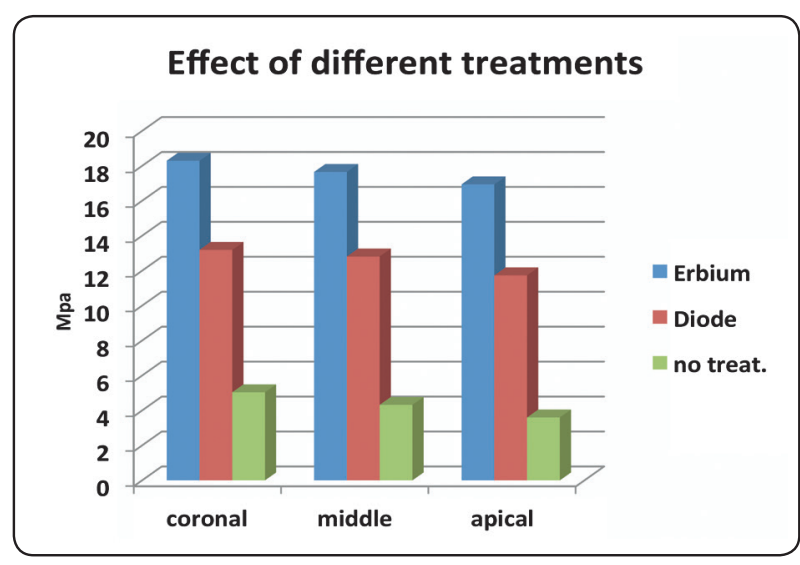

Fig. (4) Column chart showing push-out bond strength (MPa) in different treatments within the same region

Tukey's post hoc test: Within the same treatment, means sharing the same superscript letter are not significantly different

\section{Scanning Electron Microscopic Examination}

In the control group, all failures were of category 1 (adhesive failure between resin cement and root canal dentin), Whereas in the erbium-treated group, $76.7 \%$ of the failures were of category 2 (cohesive within the cement) and $23.3 \%$ were of category 3 (mixed failure). In the diode- treated group, $49.6 \%$ of failures were of category $1,26.7 \%$ were of category 2 and $23.7 \%$ were of category $3\left(\mathrm{Fig}_{\mathrm{s}} \cdot 5,6,7\right)$. 


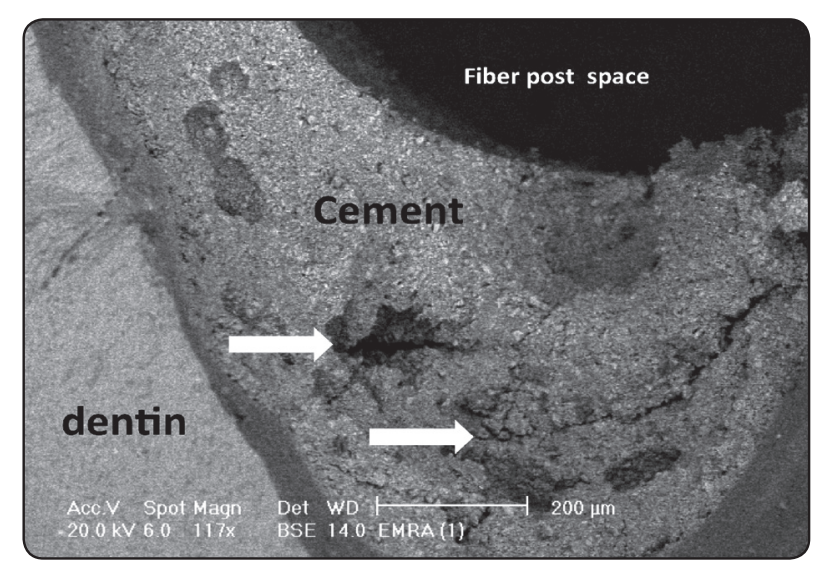

Fig (5): Representative Scanning Electron Microscope (SEM) micrograph of a cohesive failure within the cement in Erbium laser- treated sample, arrows showing a cohesive failure within the cement.

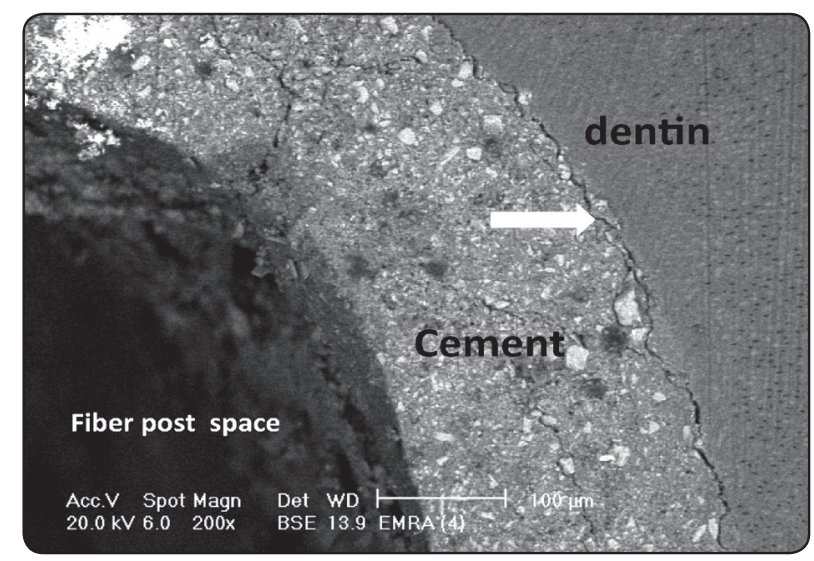

Fig (6): Representative Scanning Electron Microscope (SEM) micrograph of adhesive failure at cement/ dentin interface in Diode laser-treated sample, arrows showing adhesive failure.

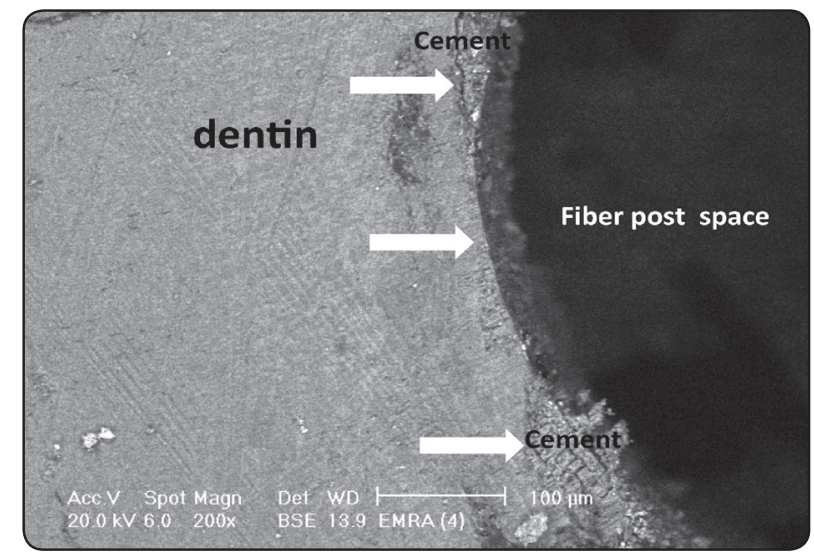

Fig (7): Representative Scanning Electron Microscope (SEM) micrograph of mixed failure within the cement and at cement/ dentin interface in Diode laser- treated sample, arrows showing mixed failure.

\section{DISCUSSION}

Given the potential of some lasers to alter dentin morphology, it is possible that they influence the strength of the bond between post and root canal dentin. ${ }^{[27,28]}$ In the present study, the push-out strength of the bond between glass fiber post and root canal dentin in human maxillary central incisors was evaluated with the use of self-adhesive cement following irradiation with Er,Cr:YSGG 2790-nm laser, 940-nm diode laser and control group (which had no laser treatment). The push-out bond strength after laser irradiation was significantly higher than in the control group, thus the first null hypothesis was rejected. The difference might be attributed to phase, compositional and microstructural changes of dentin after laser irradiation. ${ }^{[29]}$ Those findings are consistent with the results of Mohammadi et al. ${ }^{[4]}$

Wang et al ${ }^{[12]}$ and Alfredo et al ${ }^{[30]}$ found diode laser useful for removing smear layer and debris from root canals. More recently, in a study by Arisu et al, in diode laser group, the dentine surface was cleaned compared with the control group with less smear layer and debris and some dentinal tubules were opened. This was assumed to facilitate the penetration of adhesive resin and improve the pushout bond strength of the post. ${ }^{[31]}$

The effects of the heat produced by lasers during thermomechanical processes might appear as liquefaction, recrystallization, changes in the size of mineral particles, carbonization and formation of small cracks, which can influence the strength of the bond between the dentin matrix and the adhesive system. ${ }^{[32]}$ In recent years, the Er,Cr: YSGG laser has attracted a lot of attention. This laser can be effectively used to cut enamel, dentin, cementum and bone when used with water and air as cooling agents. Studies by Hossain et al have shown that in laser-irradiated dentin surfaces the orifices of the dentinal tubules are large and irregular, and no smear layer or thermal changes such as fusion and 
carbonization are visible. ${ }^{[33]}$ In contrast, Yamazaki et al reported that high-power laser irradiation led to fusion, carbonization and formation of big cracks on the root canal walls. ${ }^{[24]}$

Lin et al demonstrated that dentin hydroxyapatite particles and phases remain unchanged after laser irradiation. However, energy dispersive spectroscopy and atomic force Microscopy (AFM) phase images indicated a decrease in the organic content after laser irradiation, indicating thermal ablation of the organic component. ${ }^{[32]}$ Morphological analysis by AFM and scanning electron microscopy showed that irradiation of the root canal with the Er,Cr:YSGG laser resulted in removal of the smear layer, producing a clean and rougher surface with completely open dentinal tubules, which might affect bond strength. ${ }^{[34,35]}$ This is in agreement with values reported in the present investigation. In other study, the bond strength using a three-step total-etch adhesive system in combination with dual-cured resin cement was the same as that in the control group after Er,Cr:YSGG laser irradiation. ${ }^{[36]}$

Hence, current instrumentation techniques using rotary instruments and chemical irrigation still fall short of successfully removing the smear layer from inside the root canal system. This was confirmed by the results seen in the control group, where the conventional technique was employed. In a study by Divito et al, ${ }^{[37]}$ the Er:YAG laser showed significantly better smear layer removal than traditional technique. At the energy levels and with the operating parameters used, no thermal effects or damage to the dentin surface was observed. The Er:YAG laser with the current settings produced a photomechanical effect demonstrating its potential as an improved alternative method .

The results of the present investigation indicated that in all tested groups, the bond strength is decreasing from the coronal to the apical regions, which may be due to decreased density and the diameter of dentin tubules towards the apex. Thus, the second null hypothesis was also rejected. This is in accordance with the results of Ebrahimi et al. ${ }^{[38]}$ In two SEM studies done by Ferrari et al, it was concluded that dentin tubules density in coronal one-third is more than apical and middle one-thirds and the diameter of the dentin tubules decreases towards the apical. The hybrid layer thickness and the number of resin tags decrease from the coronal to the apical and the lateral branches of the dentin tubules are only visible in middle and coronal one-thirds. ${ }^{[39,40]}$ On the other hand, penetration of the resin is reduced in apical regions because of decreased pressure of the microbrush, and the quality of hybrid layer in apical one-third is lower than coronal and middle regions. One of the other reasons for having higher bond in the coronal region is that this region is easier to etch and apply adhesives and also is more accessible. ${ }^{[41]}$ Perdigao et $\mathrm{al}^{[42]}$ and Aksornmuang et $\mathrm{al}^{[43]}$ also indicated that the bond strength in the coronal is higher than the middle and apical regions. On the contrary, previous studies reported that the bond strength to root canal dentin with the use of self-adhesive systems was not influenced by the location in the dentin. ${ }^{[44,45]}$

The bond failure location and mode provide information about the quality of the bond between the tooth and the adhesive. In the control group, similar to the findings of some previous studies, ${ }^{[4,41}$, ${ }^{45}$ all the failures were of the adhesive type from the dentin surface. Meanwhile in the laser-treated groups, cohesive and mixed failures were registered, which is understandable given the considerable increase in bond strength after laser treatment.

Different methods are used to measure the bond strength between the resin cement and the root canal dentin such as microtensile, pushout, and pullout tests. Pushout test is based on inducing shear stress between dentin/cement and also post/cement interfaces, which are comparable with clinical situation. This test provides better estimation of the bond strength than regular shear tests since in this test 
the shear occurs perpendicular to the bond interface, so it is considered as a real shear test. ${ }^{[46]}$ Push-out test is more reliable than microtensile test because there are many premature failures in microtensile test and also the data distribution is less in pushout test. ${ }^{[47]}$ Besides, Soares et al. revealed that the pushout test is more suitable than microtensile test for evaluation of glass fiber post bonding to the root canal dentin. ${ }^{[48]}$

\section{CONCLUSIONS}

Within the limitations of this in vitro study, the following conclusions were drawn:

1. Better retention of the glass fiber-reinforced post is achievable in the coronal regions of root canals, followed by the middle, then the apical regions.

2. Laser treatment generally is an important factor in attainning improvement in bond strength of fiber post to root canal dentin.

3. The Er,Cr:YSGG 2790- nm laser afforded greater bond strength than the 940-nm diode laser.

\section{REFERENCES}

1. Schwartz RS, Robbins JW. Post placement and restoration of endodontically treated teeth: a literature review. J Endod 2004; 30 (5):289-301.

2. Ferrari M, Vichi A, Mannocci F, Mason PN. Retrospective study of the clinical performance of fiber posts. Am J Dent2000; 13 (Spec No):9B-13B.

3. Pegoretti A, Fambri L, Zappini G, Bianchetti M. Finite element analysis of a glass fiber- reinforced composite endodontic post. Biomaterials 2002; 23(13) : 2667-2682.

4. Mohammadi N, Oskoee SS, Kahnamoui MA, Bahari M, Kimyai S, Rikhtegaran S. Effect of Er,Cr:YSGG pretreatment on bond strength of fiber posts to root canal dentin using a self-adhesive resin cement. Lasers Med Sci 2013;(28):65-69.

5. Boschian Pest L, Cavalli G, Bertani P, Gagliani M. Adhesive postendodontic restoration with fiber posts: Pushout tests and SEM observation. Dent Mater. 2002;(18):596-602.
6. Akgungor G, Akkayan B. Influence of dentin bonding agents and polymerization modes on the bond strength between translucent fiber posts and three dentin regions within a post space. J Prosthet Dent. 2006;(95):368-78.

7. Ferrari M, Mannocci F. A 'one-bottle' adhesive system for bonding a fiber post into a root canal: An SEM evaluation of the post/resin interface. Int Endod J. 2000;(33):397400 .

8. Bitter K, Meyer-Lueckel H, Priehn K, Kanjuparambil JP, Neumann K, Kielbassa AM. Effects of luting agent and thermocycling on bond strengths to root canal dentine. Inter Endodon J 2006;39:809-18.

9. Aksornmuang J, Nakajima M, Senawongse P, Tagami J. Effects of C-factor and resin volume on the bonding to root canal with and without fiber post insertion. Journal of Dentistry 2011; 39:422-9.

10. Macedo VC, Faria e Silva AL, Martins LR. Effect of cement type,relining procedure, and length of cementation on pullout bond strength of fibre posts. Journal of Endodontics 2010; 36:1543-6.

11. Schoop U, Kluger W, Dervisbegovic S. Innovative wavelengths in endodontic treatment. Lasers Surg Med 2006; 38: 624-30.

12. Wang X, Sun Y, Kimura Y, Kinoshita J, Ishizaki NT, Matsumoto K. Effects of diode laser irradiation on smear layer removal from root canal walls and apical leakage after obturation. Photomed Laser Surg 2005; 23: 575-81.

13. Lee BS, Lin YW, Chia JS. Bactericidal effects of diode laser on Streptococcus mutans after irradiation through different thickness of dentin. Lasers Surg Med 2006; 38: 62-9.

14. Alfredo E, Silva SR, Ozório JE, Sousa-Neto MD, BrugneraJúnior A, Silva Sousa YT. Bond strength of AH Plus and Epiphany sealers on root dentine irradiated with $980 \mathrm{~nm}$ diode laser. Int Endod J 2008; 41: 733-40.

15. Gutknecht N, Franzen R, Schippers M, Lampert F. Bactericidal effect of a 980-nm diode laser in the root canal wall dentin of bovine teeth. J Clin Laser Med Surg 2004; 22:9-13.

16. Esteves-Oliveira M, Guglielmi CAB, Ramalho KM, AranaChavez VE, Eduardo CP. Comparison of dentin root canal permeability and morphology after irradiation with Nd:YAG, Er: YAG, and diode lasers. Lasers Med Sci2010; 25:755-760.

17. Coluzzi DJ. An overview of laser wavelengths used in dentistry. Dent Clin North Am 2000; 44:753-761. 
18. Alfredo E, Marchesan MA, Sousa-Neto MD, BrugneraJunior A, Silva-Sousa YTC . Temperature variation at the external root surface during 980-nm diode laser irradiation in the root canal. J Dent 2008; 36:529-534.

19. Sulewski JG. Making the most of the 16th Annual Conference and Exhibition: a practical orientation for attendees. Academy of Laser Dentistry 16th Annual Conference and Exhibition, 22-26 April 2009, Las Vegas, Nevada.

20. Pecora JD, Brugnera-Júnior A, Cussioli AL, Zanin F, Silva R. Evaluation of dentin root canal permeability after instrumentation and Er:YAG laser application. Lasers Surg Med 2000; 26:277-281

21. George R, Meyers IA, Walsh LJ. Laser activation of endodontic irrigants with improved conical laser fiber tips for removing smear layer in the apical third of the root canal. J Endod 2008; 34:1524-1527.

22. Lin CP, Lee BS, Lin FH, Kok SH, Lan WH. Phase, compositional, and morphological changes of human dentin after Nd: YAG laser treatment. J Endod 2001; 27(6):389-393.

23. Lee BS, Lin CP, Hung YL, Lan WH. Structural changes of Er:YAG laser-irradiated human dentin. Photomed Laser Surg2004; 22 (4):330-334.

24. Yamazaki R, Goya C, Yu DG, Kimura Y, Matsumoto K. Effects of erbium,chromium:YSGG laser irradiation on root canal walls: a scanning electron microscopic and thermographic study. J Endod2001; 27(1):9-12.

25. Arnabat J, Escribano C, Fenosa A, Vinuesa T, Gay-Escoda C, Berini L, Viñas M. Bactericidal activity of erbium, chromium: yttrium-scandium-gallium garnet laser in root canals. Lasers Med Sci 2010; 25(6):805-810.

26. Lopes GS, Ballarin A, Baratieri LN. Bond strength and fracture analysis between resin cements and root canal dentin. Aus Endo J 2012; 38 (1): 14-20.

27. Yamada MK, Uo M, Ohkawa S, Akasaka T, Watari F. Three dimensional topographic scanning electron microscope and Raman spectroscopic analyses of the irradiation effect on teeth by Nd:YAG, Er: YAG, and CO2 lasers. J Biomed Mater Res B Appl Biomater 2004; 71(1):7-15.

28. Ghiggi PC, DallAgnol RJ, Burnett LH Jr, Borges GA, Spohr AM. Effect of the Nd:YAG and the Er:YAG laser on the adhesive-dentin interface: a scanning electron microscopy study. Photomed Laser Surg 2010; 28(2):195-200.
29. Wang QQ, Zhang CF, Yin XZ. Evaluation of the bactericidal effect of Er,Cr:YSGG, and Nd:YAG lasers in experimentally infected root canals. J Endod 2007; 33(7):830-932.

30. Alfredo E, Souza-Gabriel AE, Silva SR, Sousa-Neto MD, Brugnera-Junior A, Silva-Sousa YT. Morphological alterations of radicular dentine pretreated with different irrigating solutions and irradiated with 980-nm diode laser. Microsc Res Tech 2009; 72: 22-7.

31. Arisu HD, Kivanc BH, Saglam BC, Simsek E, Gorgul G. Effect of post-space treatments on the push-out bond strength and failure modes of glass fibre posts. Aust Endod J 2013; 39:19-24.

32. Lin S, Pan D, Lin Q, Yin S, Chen D, Liu Q, Yu L, Lin Z. Evaluation of phase, microstructure and composition of human dentine after Er,Cr:YSGG laser irradiation. J Nanosci Nanotechnol 2011; 11(3):2421-2426.

33. Hossain M, Nakamura Y, Yamada Y, Kimura Y, Matsumoto N, Matsumoto K . Effects of Er,Cr:YSGG laser irradiation in human enamel and dentin: ablation and morphological studies. J Clin Laser Med Surg 1999; 17(4):155-159.

34. Tseng WY, Chen MH, Lu HH, Lin CW, Hsieh TT, Chen CH, Lai JY, Lee BS. Tensile bond strength of Er,Cr:YSGG laser-irradiated human dentin to composite inlays with two resin cements. Dent Mater J 2007; 26(5):746-755.

35. Minas NH, Gutknecht N, Lampert F. In vitro investigation of intra-canal dentine-laser beam interaction aspects: II. Evaluation of ablation zone extent and morphology. Lasers Med Sci 2010; 25 (6):867-872.

36. Nagase DY, de Freitas PM, Morimoto S, Oda M, Vieira GF . Influence of laser irradiation on fiber post retention. Lasers Med Sci 2011; 26(3):377-380.

37. Divito E, Peters OA, Olivi G. Effectiveness of the erbium: YAG laser and new design radial and stripped tips in removing the smear layer after root canal instrumentation. Lasers Med Sci. 2012; 27(2): 273-80.

38. Ebrahimi SF, Shadman N, Nasery EB, Sadeghian F. Effect of polymerization mode of two adhesive systems on pushout bond strength of fiber post to different regions of root canal dentin. Dent Res J. 2014; 11(1): 32-38.

39. Ferrari M, Mannocci F, Vichi A, Cagidiaco MC, Mjor IA. Bonding to root canal: Structural characteristics of the substrate. Am J Dent. 2000;13:255-60. 
40. Ferrari M, Vichi A, Grandini S, Goracci C. Efficacy of a self-curing adhesive resin cement system on luting glassfiber posts into root canals: An SEM investigation. Int J Prosthodont. 2001;14:543-9.

41. Zicari F, Couthino E, De Munck J, Poitevin A, Scotti R, Naert I, et al. Bonding effectiveness and sealing ability of fiber post bonding. Dent Mater. 2008; 24:967-77.

42. Perdigao J, Geraldeli S, Lee IK. Pushout bond strengths of toothcolored posts bonded with different adhesive systems. Am J Dent. 2004;17:422-6.

43. Aksornmuang J, Nakajima M, Foxton RM, Tagami J. Regional bond strength of four self-etching primer/ adhesive systems to root canal dentin. Dent Mater J. 2005;24:261-7.

44. Abo El-Ela OA, Atta OA, El-Mowafy O. Microtensile bond strength of nonmetallic dowels bonded to radicular dentin with self-etch adhesives. J Prosthodont 2009; 18(2): 167-171.
45. Bitter K, Paris S, Pfuertner C, Neumann K, Kielbassa AM. Morphological and bond strength evaluation of different resin cements to root dentin. Eur J Oral Sci 2009; 117(3):326-333.

46. Van Meerbeek B, De Munch J, Yoshida Y, Inoue S, Vargas M, Vijay P. Buonocore memorial lecture. Adhesion to enamel and dentin: Current status and future challenges. Oper Dent. 2003; 28:215-35.

47. Goracci C, Tavares AU, Fabianelli A, Monticelli F, Raffaelli O, Cardoso PC. The adhesion between fiber posts and root canal walls: Comparison between microtensile and pushout bond strength measurements. Eur J Oral Sci. 2004;112:353-61.

48. Soares CJ, Santana FR, Castro CG, SantosFilho PC, Soares PV, Qian F. Finite element analysis and bond strength of glass post to intra-radicular dentin: Comparison between microtensile and pushout tests. Dent Mater. 2008;24: 1405-11. 